\title{
Direct observation of crystallization of amorphous Mg-bearing silicate grains into $\mathrm{Mg}_{2} \mathrm{SiO}_{4}$ (forsterite)
}

\author{
K. Kamitsuji, T. Sato, H. Suzuki, and C. Kaito \\ Department of Nanophysics in Frontier Projects, Ritsumeikan University, Kusatsu-shi, Shiga 525-8577, Japan \\ e-mail: rp007988@se.ritsumei.ac.jp
}

Received 17 November 2004 / Accepted 20 January 2005

\begin{abstract}
The crystallization of amorphous Mg-bearing silicate grains into $\mathrm{Mg}_{2} \mathrm{SiO}_{4}$ and its temperature dependence were clarified by observing the grains in situ while heating in a transmission electron microscope. The crystallization started from the grain surface at $800{ }^{\circ} \mathrm{C}$. Before the crystallization at the grain surface, the formation of a rim-like layer due to prenucleation was observed. The characteristic structure change of the grains was recorded and indicated that prenucleation occurred before crystallization. This phenomenon probably corresponds to the "stall" idea suggested by Hallenbeck \& Nuth (1998, Ap\&SS, $255,427)$ in the crystallization of silicate.
\end{abstract}

Key words. astrochemistry - method: laboratory - stars: AGB and post-AGB - stars: circumstellar matter ISM: dust, extinction

\section{Introduction}

In 1996-1998, the Infrared Space Observation (ISO) project discovered infrared bands due to crystalline silicates in addition to amorphous silicates around certain stellar sources (Waelkens et al. 1996; Waters et al. 1996). Both forsterite and clino-pyroxene crystals were observed, although no ironrich silicates were observed. The crystallization of amorphous $\mathrm{Mg}$-bearing silicate grains is attracting increasing interest due to the discover of crystalline silicate grains in various astrophysical environments.

Various experiments based on gas-solid condensation from $\mathrm{Mg}-\mathrm{Fe}-\mathrm{SiO}-\mathrm{H}_{2}-\mathrm{O}_{2}$ vapors have yielded a number of phases without either olivine or pyroxene crystals (Nuth et al. 1988; Rietmeijer et al. 1999). By using infrared spectroscopy to investigate the crystallization of amorphous Mg-bearing silicate smoke grains produced in a condensation flow apparatus from $\mathrm{Mg}$ metal and a mixture of $\mathrm{O}_{2}$ and $\mathrm{SiH}_{4}$ diluted in helium and hydrogen, the temperature dependence of the spectral evolution of magnesium silicate grains has been elucidated (Hallenbeck \& Nuth 1998; Hallenbeck et al. 2000). They found that the grains have "stall" phases in their evolution via thermal annealing. The stall is indicated by a steady spectral signature in the spectral evolution. This phenomenon probably corresponds to the prenucleation process observed in the present study.

In previous works, we have demonstrated that $\mathrm{Mg}_{2} \mathrm{SiO}_{4}$ (forsterite) crystalline grains containing $\mathrm{Si}$ crystals could be produced by the coalescence of $\mathrm{Mg}$ and $\mathrm{SiO}$ smoke grains (Kaito et al. 2003). We have also suggested that single crystalline $\mathrm{Mg}_{2} \mathrm{SiO}_{4}$, polycrystalline $\mathrm{Mg}_{2} \mathrm{SiO}_{4}$, and amorphous
$\mathrm{Mg}$-bearing silicate grains are produced by the coalescence of $\mathrm{MgO}$ and $\mathrm{SiO}_{2}$ smoke grains $\left(\mathrm{MgO}-\mathrm{SiO}_{2}\right.$ system) (Kamitsuji et al. 2005). This finding suggests that the observed crystalline $\mathrm{Mg}_{2} \mathrm{SiO}_{4}$ grains and amorphous $\mathrm{Mg}$-bearing silicate grains in Red Super Giant (RSG), Asymptotic Giant Branch (AGB), post-AGB and planetary nebula (PNe) could be produced by the coalescence and growth of $\mathrm{MgO}$ and $\mathrm{SiO}_{2}$ grains. The crystalline grains produced in these experiments did not have the characteristic crystalline shape, but crystalline and amorphous grains had the same spherical shape. This indicates that amorphous Mg-bearing silicate grains were produced first and subsequently the crystallization of amorphous Mg-bearing silicates to $\mathrm{Mg}_{2} \mathrm{SiO}_{4}$ occurred in rising smoke. The appearance of crystalline and amorphous grains reflected slight variations in the cooling rate in the smoke due to the temperature gradient above the heaters. The average cooling rate of the grains produced in the $\mathrm{MgO}-\mathrm{SiO}_{2}$ system was of the order of $10^{4} \mathrm{~K} / \mathrm{s}$ (Yatsuya et al. 1984).

As has been clarified with respect to the production of quasicrystal nanograins, the cooling rate can be altered to be one order of magnitude higher by changing the gas flow velocity by introducing a pumping system at the top of the chamber (Kido et al. submitted.). In the present work, the production of amorphous grains was predominantly performed by rapid cooling of $\sim 10^{5} \mathrm{~K} / \mathrm{s}$. The crystallization of amorphous Mg-bearing silicate grains now has been directly observed by means of the in situ transmission electron microscopic method. The prenucleation process could be observed in the Mg-bearing amorphous silicate grains, although it could not be observed in the 


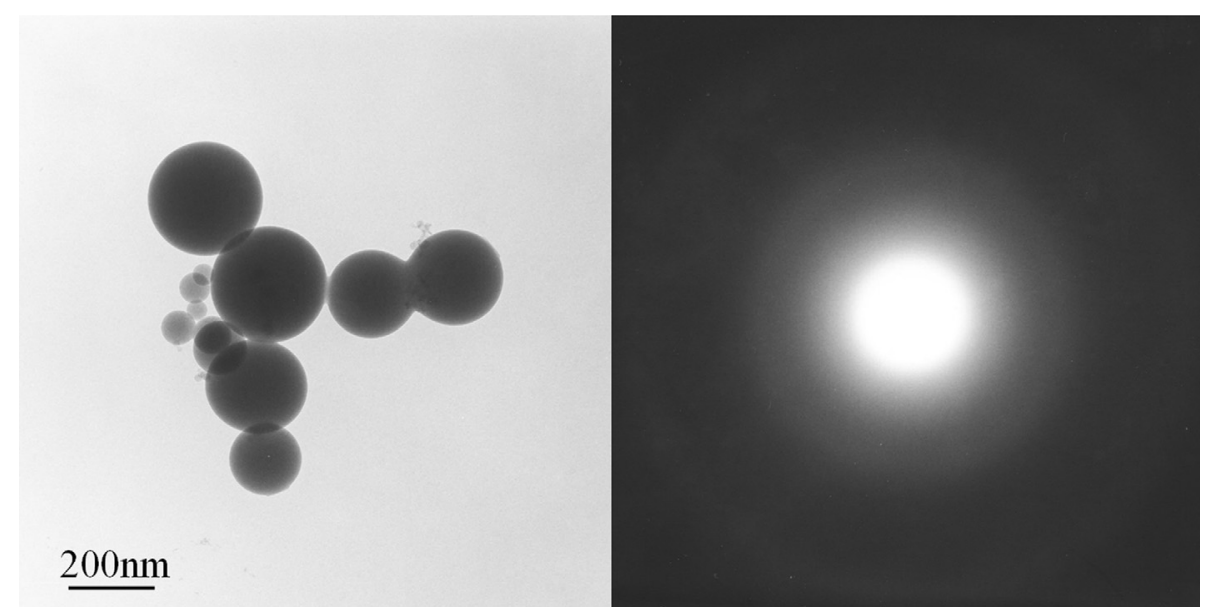

Fig. 1. Grains produced by the present method are amorphous Mg-bearing silicates.

alteration process of the amorphous $\mathrm{SiO}_{x}$ grains (Kamitsuji et al. 2004).

\section{Experimental setup}

The experimental setup for producing $\mathrm{MgO}$ and $\mathrm{SiO}_{2}$ grains and the system for bringing about their coalescence were the same as those used in a previous work (Kamitsuji et al. 2005). The evaporation chamber was a glass cylinder of $17 \mathrm{~cm}$ diameter and $30 \mathrm{~cm}$ height, covered with stainless steel on top and connected to a high-vacuum exhaust through a valve at its bottom. After evacuation of the chamber, smoke was produced by introducing a gas mixture of $\mathrm{O}_{2}$ gas at 20 Torr and $\mathrm{Ar}$ gas at 80 Torr. The gas flow velocity was varied by pumping the gas from the top of the chamber.

Collected samples were observed using transmission electron microscopes (TEM) (Hitachi H-7100R). The composition of the grains was determined using an energy-dispersive X-ray (EDX) spectrometer (Horiba EMAX-5370) attached to the H-7100R electron microscope.

The direct observation of the crystallization process was carried out using a TEM (Hitachi H-9000NAR) equipped with a heating holder which can be heated to $800{ }^{\circ} \mathrm{C}$. The temperature was raised in intervals of $50{ }^{\circ} \mathrm{C}$; each temperature was maintained for $10 \mathrm{~min}$. If the temperature of the specimen reaches equilibrium, the movement of the specimen decreases. When the phase alteration of the specimen was observed, the temperature of the specimen was then maintained constant. The images of the specimens were magnified by a factor of twenty using a television system and were recorded on video tape.

\section{Results and discussion}

In the present study, amorphous $\mathrm{Mg}$-bearing silicate grains were the predominant product in comparison to a previous $\mathrm{MgO}-\mathrm{SiO}_{2}$ system (Kamitsuji et al. 2005). Typical grains are shown in Fig. 1. Since the electron diffraction (ED) pattern exhibits a halo ring, the spherical grains were amorphous. The composition, as confirmed by EDX analysis of the amorphous grains, indicated that the atomic ratio of $\mathrm{Mg} / \mathrm{Si}$ was almost 1. Therefore, the grains were composed of amorphous
Mg-bearing silicate and they were predominantly produced at a high cooling rate.

These amorphous grains collected on the carbon thin film substrate were heated in vacuum at various temperatures for $10 \mathrm{~min}$, and their crystallization was verified by TEM. The crystallization of $\mathrm{Mg}_{2} \mathrm{SiO}_{4}$ grains was observed upon heating to $800{ }^{\circ} \mathrm{C}$ in vacuum; even if the heating was continued at $700{ }^{\circ} \mathrm{C}$ for $1 \mathrm{~h}$, no crystallization was observed.

In situ observation using a TEM was carried out and within 10 min complete crystallization was observed upon heating to $800{ }^{\circ} \mathrm{C}$. The electron microscopic (EM) image and ED pattern at $800{ }^{\circ} \mathrm{C}$ are shown in Fig. 2. Each grain was spherical, and there was no alteration of the amorphous grain shape. Bragg reflection contrasts which reflect the polycrystalline structure are clearly seen. The ED pattern indicates the crystallization of the $\mathrm{Mg}_{2} \mathrm{SiO}_{4}$ phase. The diffuse diffraction rings suggest the growth of $\mathrm{MgO}$ crystallites of the order of $5 \mathrm{~nm}$. This may be due to the small difference in the $\mathrm{Si}$ and $\mathrm{Mg}$ contents in the amorphous grains. Since the density of the amorphous material is less than that of the crystalline state, the crystallization introduces void clusters into a grain and excess amounts of $\mathrm{Mg}$ might grow into $\mathrm{MgO}$ crystallites.

The structural alteration, which occurred before the crystallization, appears in the video images, as shown in Fig. 3. During heating of the specimen, the specimen was moved until the specimen temperature reached the target temperature. The characteristic alteration of the grains was negligible during heating to $600{ }^{\circ} \mathrm{C}$. Upon heating above $650{ }^{\circ} \mathrm{C}$, a white contrast ring appeared inside the grains. This ring became increasingly clear with continued increase in temperature. The clear white contrast image obtained at $750{ }^{\circ} \mathrm{C}$ is shown in Fig. $3 \mathrm{~b}$. The ED pattern also showed halo rings under this condition. Upon heating to $800{ }^{\circ} \mathrm{C}$, the white contrast ring disappeared after $90 \mathrm{~s}$, as is shown in Fig. 3c, and crystallization occurred from the surface to the center of the grains within a delay of $90 \mathrm{~s}$ immediately following the disappearance of the white ring. The Bragg reflection contrast which confirms the crystallization can be seen in Fig. 3d.

The white contrast ring about $20-25 \mathrm{~nm}$ thick indicates the occurrence of a density change in amorphous grains due to 


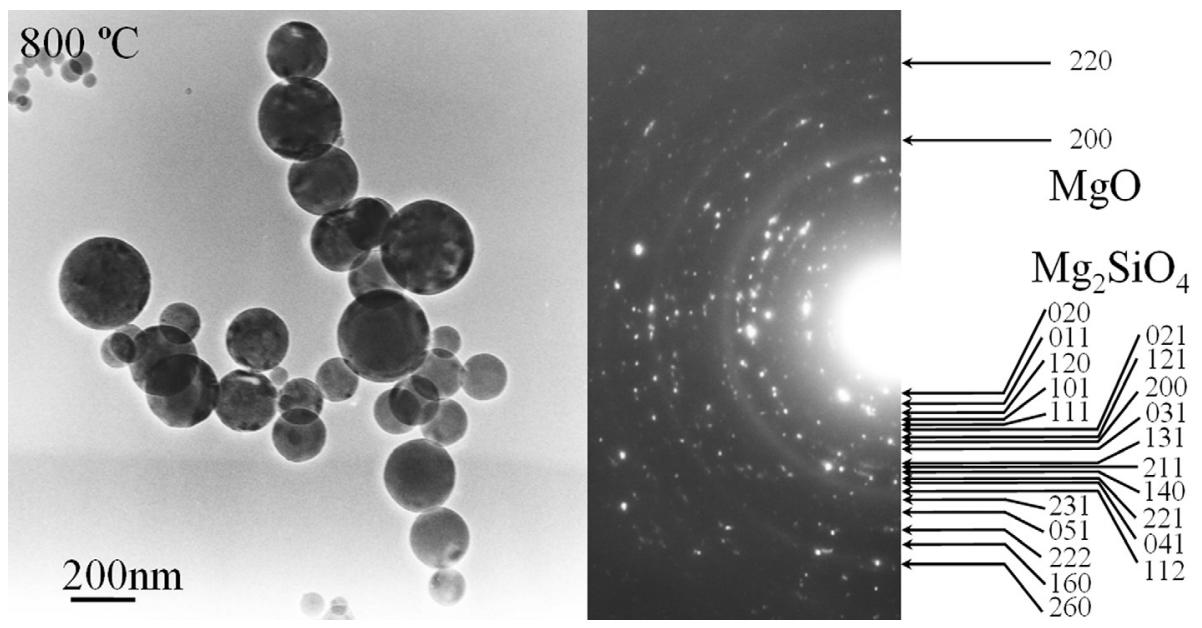

Fig. 2. Crystallized grains at $800{ }^{\circ} \mathrm{C}$; the ED pattern indicates the formation of $\mathrm{Mg}_{2} \mathrm{SiO}_{4}$.
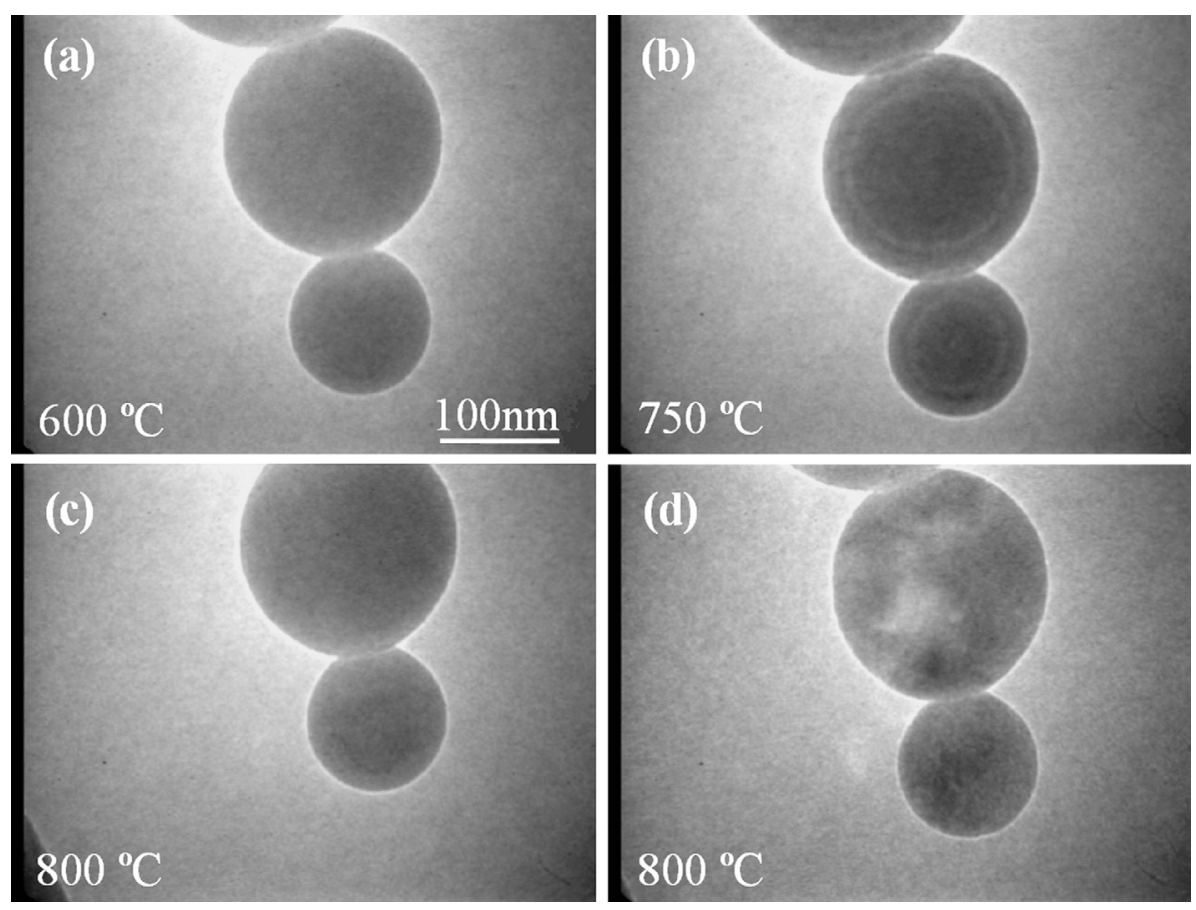

Fig. 3. Alteration of grains by heating. The appearance and disappearance of the white contrast ring are seen in b) and c). Crystallization is evident due to the Bragg reflection in $\mathbf{d})$.

prenucleation occurring at the surface layer. The density of the initial amorphous grain surface becomes greater and the movement of constituent atoms toward the surface region occurs due to prenucleation. Subsequently, the crystallization started from the surface region and progressed to the center, as shown in Figs. $4 \mathrm{a}$ and $\mathrm{b}$, which are printed stills from the video images. Crystallization of the grains started at the surface region, as indicated by the dotted region in Fig. 4a. Successive crystallization took place from the dotted region within $180 \mathrm{~s}$. Therefore, the growth velocity was approximately $1 \mathrm{~nm} / \mathrm{s}$.

The present crystallization process is considered to correspond to the stall state postulated in the papers on the infrared changes observed in magnesium silicates during thermal annealing (Hallenbeck \& Nuth 1998; Hallenbeck et al. 2000). In their papers, they showed that crystallization occurred after a stall state in magnesium silicates, and the annealing times required to enter and exit the stall state at a specific temperature could be given by specific equations. In the present experiment, the delay for the disappearance of the white ring at $800{ }^{\circ} \mathrm{C}$ was $90 \mathrm{~s}$, and crystallization started after a further interval of $90 \mathrm{~s}$. These times were determined from the video images. The calculated annealing time required to exit the stall state of magnesium silicate dusts at $800{ }^{\circ} \mathrm{C}$ was found to be almost the same: about $110 \mathrm{~s}$. Therefore, the disappearance of the white ring and the crystallization at $800{ }^{\circ} \mathrm{C}$ correspond to the exit from the stall state.

The appearance and growth of the white ring in the prenucleation process at $650-750{ }^{\circ} \mathrm{C}$ indicates the onset of the stall state. The prenucleation process means that the amorphous grains begin to undergo a structural alteration. The stall state 

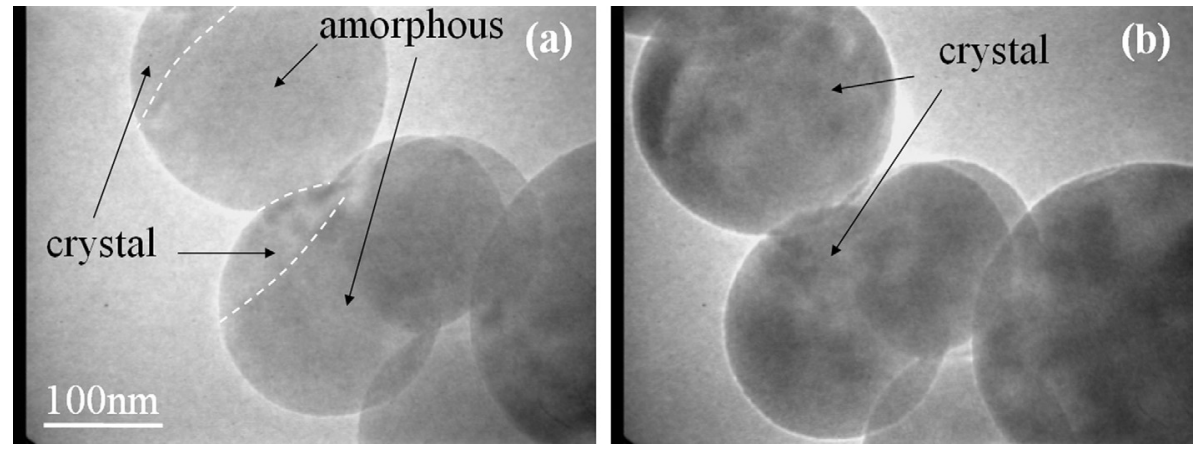

Fig. 4. Surface crystallization is seen in a) and the crystallization of the whole grain is seen in b).

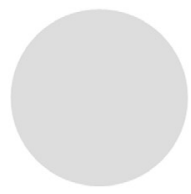

As-prepared Amorphous Mgbearing silicate particle.
The whole particle crystallizes to $\mathrm{Mg}_{2} \mathrm{SiO}_{4}$ polycrystal.

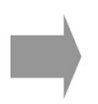

The difference in density between the surface and the center results in the appearance of a white ring due to prenucleation on the surface.

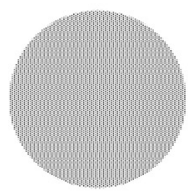

$800^{\circ} \mathrm{C}$

The disappearance of the white ring indicates that crystallization has started on the surface.

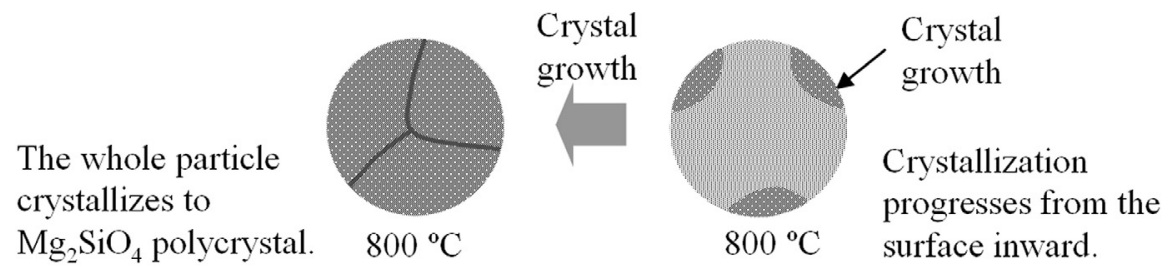

Fig. 5. Schematic model of the crystallization process of an amorphous Mg-bearing silicate grain.

indicates that the short-range order gives way to a long-range crystallographic order at the surfaces of the nanograins. The prenucleation process and stall state agree with the occurrence of a structural alteration before the grains begin to evolve toward crystallinity. However, the calculated time for the entering stall state at $650-750{ }^{\circ} \mathrm{C}$ was very long, and it was significantly different from the appearance time of the white ring. We think that there are differences in the growth process between the two experiments. In the present case, crystallization took place without any alteration of the morphology of the amorphous grains. The coagulated state of nano amorphous grains and the existence of tridymite grains as reported in the work of Hallenbeck et al. (2000) may indicate a difference in the start of the crystallization process. Therefore, the present observation of the white contrast ring can be considered to indicate the stall state.

In a similar experiment on $\mathrm{SiO}_{x}$ grains, we demonstrated that the crystalline grains of $\mathrm{Si}$ took place at the first step of grain alteration (Kamitsuji et al. 2004). The present amorphous grains may form a complete mixed Mg-bearing silicate. Therefore, the prenucleation state (stall state) can be obtained at lower temperatures.
The process of crystallization of the present amorphous grains is shown schematically in Fig. 5. The spherical shape of the grain is not changed by crystallization. This process, without shape change, possibly occurred in the crystalline smoke grains in the case of the $\mathrm{MgO}-\mathrm{SiO}_{2}$ system. Since the temperature of the smoke in the vicinity of the heat source is more than $800{ }^{\circ} \mathrm{C}$, the amorphous grains produced above $800{ }^{\circ} \mathrm{C}$ may be crystallized due to the low cooling rate of the smoke as shown in our previous work (Kamitsuji et al. 2005).

\section{Conclusions}

Amorphous $\mathrm{Mg}$-bearing silicate grains are crystallized to $\mathrm{Mg}_{2} \mathrm{SiO}_{4}$ at $800{ }^{\circ} \mathrm{C}$ with no shape change. Before the crystallization to $\mathrm{Mg}_{2} \mathrm{SiO}_{4}$, prenucleation occurs from the surface at $650{ }^{\circ} \mathrm{C}$ and this results in a difference in density between the surface and the center of the grains. This metamorphism appears as a white contrast ring. The characteristic structural change of the grains was seen as the prenucleation occurring before crystallization. This phenomenon probably corresponds to the stall state reported elsewhere (Hallenbeck \& Nuth 1998; Hallenbeck et al. 2000). 


\section{References}

Hallenbeck, S. L., \& Nuth, J. A. 1998, Ap\&SS, 255, 427

Hallenbeck, S. L., Nuth III, J. A., \& Nelson, R. N. 2000, ApJ, 535, 247

Kaito, C., Ojima, Y., Kamitsuji, K., et al. 2003, Meteor. Planet. Sci., 38,49

Kamitsuji, K., Ueno, S., Suzuki, H., et al. 2004, A\&A, 422, 975

Kamitsuji, K., Suzuki, H., Kimura, Y., et al. 2005, A\&A, 429, 205

Kido, O., Kurumada, M., Kamitsuji, K., et al., Physica E, submitted
Nuth III, J. A., Nelson, R. N., Moore, M., \& Donn, B. 1988, in Experiments on Cosmic Dust Analogues, ed. E. Bussoletti, C. Fusco, \& G. Longo (Dordrecht: Kluwer), 191

Rietmeijer, F. J. M., Nuth III, J. A., \& Karner, J. M. 1999, ApJ, 527, 395

Waelkens, C., Waters, L. B. F. M., de Graauw, M. S., et al. 1996, A\&A, 315, L245

Waters, L. B. F. M., Molster, F. J., de Jong, T., et al. 1996, A\&A, 315, L361

Yatsuya, S., Yanagida, A., Yamauchi. K., \& Mihama, K. 1984, J. Cryst. Growth, 70, 536 